\title{
Firm Resources, Core Competencies and Sustainable Competitive Advantage: An Integrative Theoretical Framework
}

\author{
Lydiah Wanjiru Kabue ${ }^{1} \&$ James M. Kilika ${ }^{1}$ \\ ${ }^{1}$ Department of Business Administration, Kenyatta University, Nairobi, Kenya \\ Correspondence: James M. Kilika, PhD, Lecturer, Department of Business Administration, Kenyatta University, \\ Nairobi, Kenya.
}

Received: February 9, 2016

Accepted: February 17, $2016 \quad$ Online Published: February 19, 2016

doi:10.5430/jms.v7n1p98

URL: http://dx.doi.org/10.5430/jms.v7n1p98

\begin{abstract}
A number of studies based on the Resource Based View (RBV) consider resources as the only sources of gaining a source of a firm's sustainable competitive advantage. According to the RBV approach, there are qualities that resources must possess in order for them to realize sustainable competitive advantage for a firm. The resources must be valuable, rare, inimitable and immobile across firms. Since resources are more often common than rare, more homogenous than heterogeneous and more mobile than immobile, then firms have to combine the resources in order to develop rare and difficult to imitate processes that will act as a source of sustainable competitive advantage. In an industry where resources are common and mobile, a firm therefore needs to build competencies in order to convert these common and mobile resources into processes that are rare and immobile to create a source of sustainable competitive advantage for the firm. A problem therefore exists for firms in a homogenous industry where resources are shared and are neither rare nor heterogeneous across firms in the industry to develop sources of sustainable competitive advantage. In order for these firms to develop sources of competitive advantage with the resources available to them, they would need to develop core competencies to turn the non rare homogenous resources into rare and heterogeneous processes that competitors cannot imitate. The development of these competencies is the product of organizational cultures and values formed over time which can be explained by institutional theory. Further, a firm may not own the resources they need to form a source of sustainable competitive advantage. These resources may be owned by other firms not controlled by the firm in need of these resources which is a premise of the institutional theory. While this is acknowledged from the existing literature, there is also lack of an integrated theoretical model to demonstrate how diverse theories explaining firm strategic behaviour may be utilized to enable firms build sustainable competitive advantage. This paper proposes an integrated theoretical model for linking firm resources with core competencies and sustainable competitive advantage while providing for the role of the firm's external environment. The proposed model integrates the postulates of the RBV, RDT, Institutional Theory and Porter's five forces Model. The emerging theoretical propositions and implications for future research are discussed.
\end{abstract}

Keywords: firm resources, core competencies, sustainable competitive advantage, Resource Based View Theory

\section{Introduction}

The Resource based view explains how a firm is able to gain a competitive edge using resources available to the firm. According to Barney (1991) a strategic resource meets certain criteria - it is valuable, such that it reduces costs or increases value to customers. It is also rare enough such that competitors do not use the same resource to compete away the value. A strategic resource is also difficult to imitate or substitute. This quality of inimitability keeps competitors from gaining parity. Barney (1991) further argues that if resources are mobile and homogenous across the industry, it is not possible to conceive a competitive advantage since any other firm with the same resources can conceive the same strategy and implement it.

Teece and Pisano (1997) assert that companies gain and sustain competitive advantage due to the ability to renew, integrate and expand their existing competences and continuously develop new capabilities. According to Banerjee (2003), a core competence is the ability of an organization to operate efficiently within the business environment and to respond to challenges. Prahalad and Hamel (1990) explain that to get to the future fast, top managers must either see opportunities, by virtue of pre-emptive and consistent capability - building that other companies cannot copy. The concept of core competencies thus plays an important role in relating or transforming resources into sustainable 
competitive advantage for a firm. In addition as Enz (2008) argues, a single resource cannot be a source of competitive advantage. Rather multiple resources need to be organized in novel ways to create a firm's capabilities. This calls for a process of bundling the resources which management can do through the process of acquisition, development, management and discarding of resources. Competitive advantage developed this way is difficult to imitate by competitors since competitors are often unable to determine exactly how the source of capability was created.

In support of this, Barney (2001) explains that one of the sources of competitive advantage in a firm is its ability to be creative and entrepreneurial in order to discover how to generate value with its resources in ways that other firms and outside owners cannot anticipate. Rumelt and Lippman (1982) posit that competitive advantage can only be sustained if the capabilities creating the advantage are supported by resources that are not easily replicated by competitors. Managerial abilities are important to a firm and they are key distinctive competencies that the firm can use to develop and sustain competitive advantages. According to Teece (1994) sustainable advantage requires not only the ownership of difficult to replicate assets but also unique and difficult to replicate dynamic capabilities. Core competencies are resources and capabilities that serve as a source of competitive advantage for a firm over its rivals. Competencies act as a linkage between the firm's internal resources and the current environment. Though two firms might have the same resources, employing these resources to meet market needs will make one firm successful and the other not so. The role of competence building in a firm is therefore of utmost importance.

Danneels (2002) identifies two types of competencies i.e. technological and customer competencies. A technological competence is the ability of a firm to make certain physical products whereas a customer competence enables the firm to serve a particular customer group. Some firms are able to enter new markets while others stay bound to their current customers. On the other hand, other firms continuously develop new technologies while others stay bound to obsolete technology.

Huang, Dyerson, Wu and Harindranath (2015), note that formerly stable environments are becoming uncertain as a result of accelerating technological change, globalization, industry convergence, aggressive competitive behaviour and deregulation. Since firms need to possess rare, inimitable and heterogeneous resources in order to develop a source of sustainable competitive advantage, then a challenge exists for firms operating in an industry where resources are mobile and homogeneous across firms. While it is important for firms to possess valuable, rare, difficult to imitate and immobile resources to develop initial sources of competitive advantages, for these competitive advantages to be sustained, the firm must develop core competencies that will keep on regenerating rare, non imitable and immobile processes that are difficult for competitors to imitate.

While the RBV maintains that a firm's sustainable competitive advantage is derived from its resources, cases exist where firms do not control the resources they need. This is explained by the Resource Dependence Theory. On the other hand the institutional theory explains how firms secure their positions and legitimacy by conforming to the norms and rules of the institutional environment. This helps build competencies that give one firm unique competencies that act as a source of sustainable competitive advantage. Complementarities therefore exist between the three theories and there is a need to explore how each complements the shortcomings of the other. The study is of the view that a firm in an industry with no valuable, rare, heterogeneous and inimitable resources may develop key competencies that will be a source of competitive advantage for the firm. Thus the unique role of developing competencies while combining key resources to generate competitive advantage from firms' processes needs consideration by theorists and researchers. In addition while undertaking this, the existing complementarities suggested by proponents of diverse theories explaining firm strategic behaviour also need to be given attention.

The objective of the study therefore is to first review the extant theoretical and empirical literature on the linkage between firm resources, core competencies and competitive advantage. Secondly the study seeks to identify emerging theoretical and empirical gaps on the linkage between firm resources, core competencies and competitive advantage. Lastly the study proposes a conceptual framework for linking firm resources, core competencies and competitive advantage. Undertaking a study in this direction is considered valuable in a number of ways. First, the paper goes beyond the scope of the extant theoretical and empirical literature to show the theoretical linkages between resources, the mediating conditions of competencies and sustainable competitive advantage. This is considered necessary to inform empirical endeavours that rely on the input of the RBV to explain firm strategic behaviour. Secondly, the paper considers calls made in previous research regarding areas of complementarities among the diverse theories explaining firm strategic behaviour. While these previous works have alluded to evidence on such complementarities, they have not indicated how the contributions of the theories are applicable in identifying 
these complementarities (Meyer, Estrin, Bhaumik, \& Peng, 2009b; Kilika, 2012). The proposed theoretical model and propositions of the paper further extends these previous attempts.

\section{Review of Relevant Theories}

The arguments of the paper are anchored on several theories that focus on resources and their management to achieve competitive advantage. The RBV maintains that the only sources of competitive advantage in a firm are the resources. Further it explains the qualities and characteristics that these resources must possess in order for them to first be a source of competitive advantage and second for this source of competitive advantage to be sustainable. Barney (1991) argued that firms that possessed resources that were valuable and rare would attain competitive advantage and enjoy improved performance in the short term. In order for a firm to sustain these advantages over time its resources must also be inimitable and non substitutable. According to Newbert (2008) the RBV sees exploitation of valuable rare resources as the main contributor to a firm's competitive advantage which in turn contributes to its performance. According to Hoffer and Schendel (1978), resources possessed by a firm are the primary determinants of its performance and they may contribute to a sustainable competitive advantage of the firm. The central premise of the RBV is that firms compete on the basis of their resources and capabilities (Petraf, 1993). However, firms do not always own or control the resources that they need in order for them to develop a source of sustainable competitive advantage. These resources might be owned by firms not in direct control by the firm needing them.

To this extent the RBV best exhibits some inherent weaknesses and so the need to consider the case of externally controlled resources by others through the lense of the RDT. Pfeffer and Salancik (1978) describe the Resource Dependence Theory (RDT) as the study of how external resources of organizations affect the behaviour of the organization. The RDT argues that organizations depend on resources which are often in the hands of other organizations. Bartol and Martin (1988) look at another aspect of resource dependence and explain that as a result of division of labour, management also depends on the resources such as work effort, expertise, and organizational connections provided by individual employees, work groups or departments. Pfeffer (1992) further argues that the degree to which management depends on any employee is defined as the inverse of the power that same employee has over his or her manager. Employees are capable of competence building in the organization. Competence building can create a source of sustainable competitive advantage for the firm.

When a firm does not possess the required resources to achieve competitive advantage, one of the options available to it is outsourcing. Outsourcing can be done when a firm does not have capabilities in the areas needed to succeed or when a firm lacks a resource or possesses inadequate skills essential to successfully implement a strategy. When organisations do not possess resources and capabilities required in developing a source of competitive superiority in all primary and support activities necessary to compete then they can acquire the same from external providers. Outsourcing of these key skills can create a source of sustainable competitive advantage for the firm. The RBV and the RDT, however, do not take into consideration the use of key competencies in developing rare, inimitable processes from common and mobile resources to create a source of competitive advantage for the firm. The institutional theory explains how firms develop processes and practices through organizational cultures formed over time.

The institutional theory explains how a firm forms organizational cultures and practices over time. According to Meyer and Rowan (1991), various groups and organisations better secure their positions and legitimacy by conforming to the norms and rules of the institutional environment. These practices and cultures are historical and difficult for other organizations to imitate. The practices can be a source of sustainable competitive advantages for the firm since they are intangible. Intangible resources are the best in building core competencies for firms. Institutional theories can affect firm strategy either negatively or positively. Where there is pressure to conform to certain set rules and regulations especially on product and service standards then institutional theories may impact positively on organizational performance. The institutional theory therefore explains the process through which firms develop key competencies over time that act as a source of competitive advantage. The institutional theory explains how firms adapt to the environment around them. This environment includes the whole industry, regulatory bodies, buyers and suppliers. Porter's five forces model therefore complements the institutional theory in explaining how a firm assesses the attractiveness of the industry in which it is operating.

According to Porter (1980), a firm can assess the attractiveness of an industry through an analysis of five forces. The first of these forces is the strength of the threat of new entrants to the industry. Second is the threat of substitute products. Third is the power of buyers or customers. Fourth is the power of suppliers and fifth is the degree and nature of rivalry among businesses in the industry. Porter (1985) argues that on the basis of analysis of these forces, 
an organization can develop a generic competitive strategy of differentiation or cost leadership capable of delivering superior performance through an appropriate configuration and co-ordination of its value chain activities. A cost leadership strategy requires a firm to become the lowest cost producer of a product or service so that above-average profits are earned even though the price charged is not above the industry average. A differentiation strategy on the other hand involves creating a customer perception that a product or service is superior to that of other firms based on brand, quality and performance so that a premium price can be charged to customers. A focus strategy involves the use of either a differentiation or cost leadership strategy in a narrow market segment.

Porter (1985) argues that a firm must choose between a differentiation or cost leadership strategy. He argues that to be stuck in the middle between the two is likely to result in failure. However, firms can successfully develop both low cost and differentiated products for different market categories and this can be their source of competitive advantage. Mintzberg (1995) argues that low cost and low price alone do not sell products and services. They must possess qualities perceived by customers as desirable and of value. Prices combined with image, after sales support, quality and design can be used as the basis for product differentiation. Development of these strategies is a core competence that puts one firm apart from another in an industry where key resources are common across firms.

From the discussion on the postulates of the relevant theories that explain firm strategic behaviour in the manner that involves resources leading to sustainable competitive advantage, the authors observe that even though the theories are rich in content and prescription, such content needs to be utilized in theoretical work to guide empirical work among scholars so as to inform strategic management practices in organizations. From the theories therefore, it is important to identify the relevant set of constructs that feature in the firm strategic behaviour and demonstrate how these are connected in a logical phenomenon. In view of this observation, the paper next considers these constructs and explains each so as to demonstrate how they fit in a phenomenon that is anchored on the postulates of the relevant theories.

\subsection{Conceptualization of Key Constructs}

A review of literature on the supporting theories reveals four key constructs that emerge. The concepts forming the basis of the study include firm resources, competence building, sustainable competitive advantage and environmental factors. The three are interlinked and each aids the other in value creation for the firm. In order for a firm to gain a source of sustainable competitive advantage, it requires resources. The resources need to be organized in such a way that competitors are not able to imitate. The organization of resources in a way that they add value to the firm requires core competencies. Below is a brief discussion on each one of the four constructs; firm resources, competence building, sustainable competitive advantage and enviromental factors.

\subsubsection{The Concept of Firm Resources}

A firm needs resources in order for it to develop sources of competitive advantage. These resources are used in combination to develop products and services that are valuable to the customer. Porter (1981) describes firm resources as strengths that firms can use to conceive of and implement their strategy. While some firm resources may lead an organisation to conceive of and implement strategies that reduce its effectiveness and efficiency, other resources may have no impact on how a firm lays out strategies. Zott and Amit (2007) define resources as stocks of available factors that are owned or controlled by the firm which are converted into final products or services.

Firm resources are all the assets, capabilities, organizational processes, firm attributes, information and knowledge which are controlled by the firms that enable them to conceive and implement strategies that improve efficiency and effectiveness (Barney, 1991). A strategic resource meets certain criteria - it is valuable, such that it reduces costs or increases value to customers. It is also rare enough such that competitors do not use the same resource to compete away the value. A strategic resource is also difficult to imitate or substitute. This quality of inimitability keeps competitors from gaining parity. The resources must also be heterogeneous and immobile across the industry. Where resources do not have these required characteristics then managers have to apply their knowledge and skills to develop a set of competencies that will set them apart from their competitors.

The quality of heterogeneity in resources makes it difficult for competitors to imitate. According to Barney (1991) heterogeneity of firm resources makes it difficult to measure competitive advantage of individual resources that should meet the following criteria; add positive value to the firm, be unique, be imperfectly imitable and non-substituted by other resources. According to Hoffer and Schendel (1978), resources possessed by a firm are the primary determinants of its performance and they may contribute to a sustainable competitive advantage of the firm. Some empirical attempts made towards this direction highlight some concerns for theory and empirical work. For example, Sirmon, Hitt, Ireland and Gilbert (2011) carried out a study on resource orchestration to create competitive 
advantage. The purpose of the paper was to develop an additional theory in order to understand the actions managers take to manage a firm's resources. The article also contributed to Resource Based View theory by discussing the integration of resource management and asset orchestration to form a more comprehensive framework termed resource orchestration. The study however did not bring out the key underlying activities that managers undertake in order to successfully achieve resource orchestration. The important role played by organizational culture and learning in shaping managerial decision making process was not put into consideration.

\subsubsection{The Concept of Competence Building}

Competence refers to a firm's capacity to deploy resources, usually in combination using organisational processes to produce a desired effect. Competence allows resources to be utilized and creates the potential for output. Resources are a source of capability for the firm but competence to use the resources to acquire economic rent is the main source of competitive advantage for the firm. Core competencies should be difficult for competitors to copy. In order to achieve competitive advantage competencies need to be managed and utilized. The top management in any firm must be able to identify, cultivate and exploit core competencies. Learning gained from skills accumulated over a long time is a core competency.

Competence is the ability to match firm specific capability and market needs. Environmental changes make previously acquired competences obsolete or create new opportunities. If new opportunities are created by environmental changes then this would call for development of new competences to drive the firm in the right direction towards achieving new competitive advantages. A firm must therefore continuously build new competencies to match the changing environment in order for it to sustain its competitive advantages. Penrose (1959) describes firm development as an evolutionary and cumulative process of resource learning in which increased knowledge of the firm resources enables further expansion and increase of absorptive capacity. Competence allows for one firm to use the same set of resources in a particular way to gain competitive advantage and for a different firm to employ the same resources in a less potential way. Competence is the capacity of a firm to convert the resources they posses into services. Competencies therefore enable firms develop processes that enable them develop competitive advantages over their rivals.

In a study conducted by Danneels (2008) focusing on the role of organizational antecedents of second order competences in building new customer and technological competences respectively, it was found that second order competences are related to exploration which entails learning activities that lead to addition of new resources. The study identified five organizational characteristics that facilitate exploratory learning. These are; a) The willingness to cannibalize, b) The presence of constructive conflict in the organization, c) A climate of tolerance for failure d) The extent to which the firm engages in environmental scanning and e) The firm's slack resources. Ljungquist (2013) carried out a study on the core competence concept on links, levels, time and context, knowledge and process management. The study proposed a core competence management model designed to handle complex innovation processes in fast paced market dynamism. In particular the study focused on the core competence concept from different perspectives; innovation outcome types and modes of development, ambidextricity, and time dimension of shared history and shared future aims, task force team's degree of homogeneity and degree of formal structural setting. The study proposed that existing core competencies are ideally explored by homogenous teams managed at the SBU level in structured context which infers competitive imitation protection. Emerging from the conceptualization of this study is the fact that, even though the process of competence building requires an aspect of learning, how the input of the learning organization concept is integrated is not clearly pointed out despite the fact that proponents of this learning concept have suggested that it holds huge potential for firm competitiveness (Pedler, Boydell \& Burgoyne 1991; Garvin 1993).

\subsubsection{The Process of Building Sustainable Competitive Advantage}

The ultimate aim of firms is to attain superior performance. In order for this to happen, a firm in an industry must have a source of competitive advantage that is difficult for other firms in the industry to imitate. A firm that hopes to have a sustainable source of competitive advantage must develop strategies that will help it combine its resources in a way that competitors cannot imitate. Barney (1991) explains that this can be achieved through heterogeneous resources in an organization. Firms can develop various strategies that will help them develop sustainable competitive advantage and this can be first movers, barriers to entry, low cost or differentiation.

According to Porter (1980), there are factors that allow a firm to assess both the attractiveness of its industry and its competitive position within that industry through an evaluation of five forces. These are the threat of new entrants, threat of substitute products, power of buyers, power of suppliers and rivalry between members of the industry. An analysis of these factors allows the firm to choose the strategy to adopt. Porter (1980) proposed the concepts of cost 
leadership and differentiation relative to competitors as two important sources of competitive advantage. The argument is that a low cost position enables a firm to use aggressive pricing and high sales volume which can be achieved through economies of scale. Differentiation on the other hand allows for differentiated products to create brand loyalty and positive reputation and therefore enables premium pricing.

Ghemawat (1986) also explains that competitive advantage can be achieved by either moving in early to the market or moving in to the market in large scale. If a firm either moves in early to the market or in large scale, it may pre-empt the market by setting new standards or by gaining access to critical raw materials, locations, production capacity and customers. Hamel and Prahalad (1994) observe that competitive advantage can also be gained by competing for the future. Firms must not only be concerned with the present day profitability but also profitability both in the medium and long term profitability as their source for competitive advantage. These views require that firms lay out strategies on how they will compete when their current strategies become either obsolete or are copied by competitors. The role of the external contexts as argued for by Porter even though they play a role in competitiveness, extant research has to a great extent ignored its role.

In one of the attempts, Sillince (2006) carried out a study aimed at assessing the influence of Resources and Organizational Identities on the role of rhetoric in creation of competitive advantage. The author presented a model that attempted to demonstrate how rhetoric can switch the audience's attention between identities and resources to gain competitive advantage. The purpose of the paper was to demonstrate how firms rhetorically link resource attributes of value, rarity, non-imitability and non substitutability by using multiple organizational identities. The author illustrated how multiple identities provide clear action guidelines to practitioners by integrating the communication and management literatures on rhetoric with literature on the Resource Based View thus adding a new dynamic to the scholarship of organizational rhetoric. The study indicated that multiple organizational identities link to competitive advantage. The study however, did not demonstrate the role played by environmental factors in complementing the RBV. The study could also have demonstrated how each identity would lead the firm in identifying the generic strategy to adopt.

One more recent study by Huang, Dyerson, Wu and Harindranath (2015) sought to explain how Temporary Competitive Advantage (TCA) is turned to Sustainable Competitive Advantage (SCA). The purpose of the study was to integrate both the industrial organization theory and the resource based view theory in the analysis of competitive advantage at the firm level. The study clarified a conceptual distinction between two types of competitive advantage - Temporary Competitive Advantage (TCA) and Sustainable Competitive Advantage (SCA). The study explored how firms transform temporary competitive advantage into sustainable competitive advantage. The paper examined the causality between TCA and SCA based on the existence of SCA which is increasingly accepted by theorists. The research attempted to provide an integrative view of Industrial Organization Theory and RBV to shed light on competitive advantage over a period of time as well as to explain how a firm accumulates its TCA to achieve SCA. However, in their conceptualization, the authors did not focus on the exact contribution made by each theory so as to point at the role of the external environment, an observation that could be interpreted to raise some serious ontological and epistemological points of concern.

\subsubsection{The Role of Environmental Factors}

Firms do not exist in isolation but are run within an environment made up of other firms in the same industry and other industries. There also exist governing bodies and organizations and sets of laws within which the firm must operate. There are certain cultural practices, legal environments, traditional and historical factors that shape the firm and influence its activities. According to Porter (1980), there are five forces that allow a firm to asses both the attractiveness of its industry and its competitive position within that industry. First is the strength of the threat of new entrants to the industry. Second is the threat of substitute products. Third is the power of buyers or customers. Fourth is the power of suppliers (to firms in the industry) and fifth is the degree and nature of rivalry among businesses in the industry. Developments along these forces negatively affect the potential of a firm to be successful. Porter (1985) argues that on the basis of analysis of these forces, an organization can develop a generic competitive strategy of differentiation or cost leadership capable of delivering superior performance through an appropriate configuration and co-ordination of its value chain activities which leads to an important premise that consideration of the external environment is a critical factor in the path towards development of sustainable competitive advantage.

Thus, the above review of literature on relevant theories and key constructs reveals that there is a possible relationship between firm resources and sustainable competitive advantage. The authors have proposed a theoretical model to explain the relationship between firm resources and sustainable competitive advantage. The review of literature also reveals that the environment plays an important role in development of core competencies that lead to 
sustainable competitive advantage. The framework illustrates the linkage between firm resources, core competencies and sustainable competitive advantage.

\section{Proposed Theoretical Framework}

The proposed theoretical framework below demonstrates the linkage between firm resources, core competencies and sustainable competitive advantage. It also brings in the role played by the environment in strategic decision making by firms.

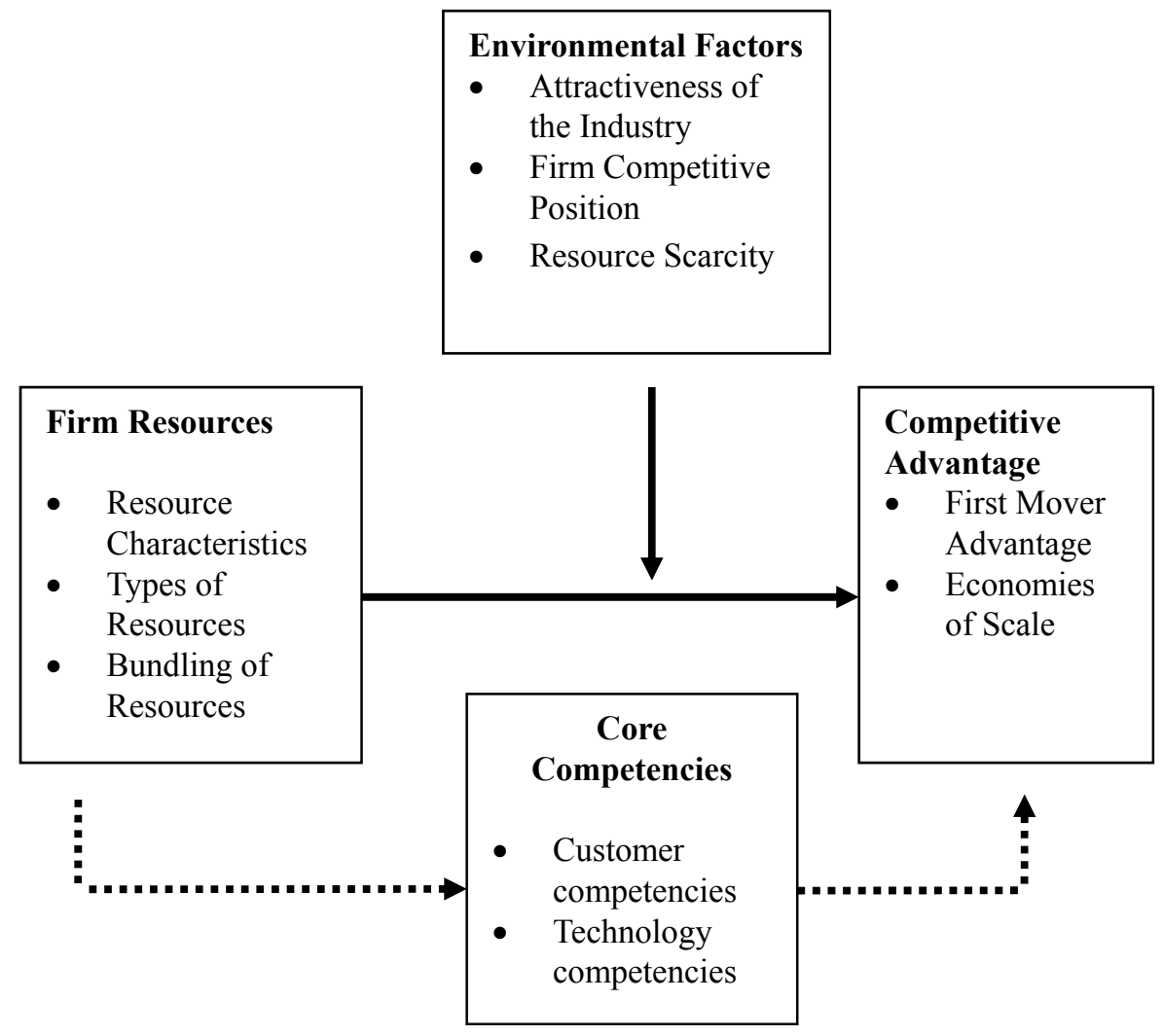

Figure 1. Theoretical model linking firm resources, core competencies and competitive advantage

The proposed theoretical model demonstrates a direct causal relationship between firm resources and sustainable competitive advantage. However, the model illustrates that core competencies such as inimitable structures, values and organisational practices that are not mobile across firms, heterogeneous and rare processes mediate the relationship between firm resources and sustainable competitive advantage. Further environmental factors such as resource scarcity, a firm's competitive position and the industry's attractiveness moderate the relationship between firm resources and sustainable competitive advantage. Below is a discussion on the linkages between the variables.

\subsection{Firm Resources and Competitive Advantage}

A firm can use its resources to develop sources of competitive advantage. In order for a resource to be a source of competitive advantage, it must possess certain qualities. According to Barney (1991), the resource needs to be valuable, rare, immobile and heterogeneous. Since rare resources are rare and most resources are shared across firms in the industry, a firm can use resources in combination to form core competencies which will be their source of competitive advantage. The resources for the firm include land, equipment, labour and capital. Labour includes top managers and other employees' capabilities and knowledge. Capital includes both tangible and intangible resources. Tangible resources are assets that can be observed and quantified. Examples are financial assets and organizational assets. Intangible resources are assets that typically are rooted deeply in the firm's history and have accumulated over time. 
A competitive advantage based on an intangible resource is more difficult for competitors to imitate and therefore a source of sustainable competitive advantage. These include human resources, innovation resources and reputational resources. Grant (2001) explains that human resources provide services to the firm in the form of skills, expertise, knowledge and decision making capability. These human resources are responsible for building core competencies for the organization by utilizing both knowledge and skills that they accumulate over time. A firm can for instance use intangible resources like skills, knowledge and expertise to develop rare processes that will be difficult for competitors to imitate.

Firm resources are necessary in a firm in order for the firm to develop a source of sustainable competitive advantage. For resources to be a source of sustainable competitive advantage they must be valuable, rare, inimitable and heterogeneous. Since resources are more often common than rare, more homogenous than heterogeneous and more mobile than immobile, then firms have to combine the resources in order to develop rare difficult to imitate processes that will act as a source of sustainable competitive advantage.

In order to develop sustainable competitive advantage, a firm needs to be responsive to rapidly changing market conditions by maintaining the development of existing resources and capabilities and creating new ones. This can be done by employment of core competencies to continuously develop new capabilities from existing resources. Core competencies can also be employed to develop either a cost advantage or a differentiation advantage. Porter (1980) developed the concept of cost leadership and differentiation relative to competitors as two important sources of competitive advantage. This can result to either production of low cost products or services or to differentiated products or services which will result into a sustainable competitive advantage for the firm.

Proposition 1 -Diverse Firm Resources that demonstrate attributes of strategic assets will contribute to sustainable competitive advantage among firms that possess the resources.

\subsection{The Role of Core Competencies}

Core competencies are the activities that a firm performs well relative to its competitors, adding unique value for its customers. Core competencies are developed by combining firm resources and can act as a source of competitive advantage in a firm. Competency is the ability of the firm to match firm specific capability and market needs. Enz (2008), observes that resources and capabilities only have potential if organizational systems exist that allow the realization of potential. The employment of these organizational systems that are firm specific is the building of core competences. In a homogenous industry employment of particular core competencies by one firm may result to development of competitive advantages over the other firms.

Use of intangible resources like knowledge and skills can help a firm convert its common and mobile resources into a set of competencies that will be difficult for the competition to imitate and therefore act as a source of sustainable competitive advantage for the firm. Hodgson (1998) in explaining the competence based perspective sees the existence, structure and boundaries of the firm as explained in some way by the associated existence of individual or team competencies such as skills and tacit knowledge which are fostered and maintained by that organization. Skills and tacit knowledge are key in development of core competencies that a firm can employ in combining its resources and capabilities to gain sources of sustainable competitive advantage.

A firm can develop core competencies over time and turn imitable resources into costly to imitate capabilities. Non-imitable capabilities are a source of competitive advantage for the firm. Competitor firms are not able to tell how the firm employs its capabilities as foundations for competitive advantage. Core competencies are the activities that a firm performs well relative to its competitors, adding unique value for its customers. Core competencies only represent the resources and capabilities of a firm that have strategic value. Core competencies are derived from valuable capabilities, rare capabilities, costly to imitate capabilities and non substitutable capabilities.

Proposition 2 - Though firm resources lead to sustainable competitive advantage, core competencies determine the strength of the relationship between the two.

\subsection{The Influence of the Environment}

Though resources are important in creation of sustainable competitive advantage for firms, it is not possible to overlook the important role played by the environment within which the firm is doing business. This environment both in and outside the firms industry constitutes of other players and factors that influence how certain businesses are run. These factors can be socio-cultural or political and firms must take them into consideration in the process of making strategic decisions. There also exist governing bodies and organizations and sets of laws within which the firm must operate. There are certain cultural practices, legal environments, traditional and historical factors that shape the firm and influence its activities. 
Increased competition, lower barriers to entry, a large number of substitutes and increased bargaining power of customers and suppliers negatively affects the potential of a firm to be successful. Porter (1985) argues that on the basis of analysis of these forces an organization can develop a generic competitive strategy of differentiation or cost leadership capable of delivering superior performance through an appropriate configuration and co-ordination of its value chain activities.

A cost leadership strategy requires a firm to become the lowest cost producer of a product or service so that above-average profits are earned even though the price charged is not above the industry average. A differentiation strategy on the other hand involves creating a customer perception that a product or service is superior to that of other firms based on brand, quality and performance so that a premium price can be charged to customers. A focus strategy involves the use of either a differentiation or cost leadership strategy in a narrow market segment.

Proposition 3 - The context within which the firm operates will moderate the relationship between the firm's resources and its level of competitive advantage.

\section{Conclusion}

The purpose of this theoretical paper was to review both extant theoretical and empirical literature, on the linkage between firm resources, core competencies and competitive advantage. The study also sought to identify emerging theoretical and empirical gaps on the linkage between firm resources, core competencies and competitive advantage. Extant literature reviewed indicates that a firm must have resources in order for it to develop sources of sustainable competitive advantage. The literature reviewed also indicates that core competencies are used by firms in ways that competitors do not understand to act as a source of competitive advantage. A firm therefore uses its resources in combination with core competences to achieve sources of sustainable competitive advantage. The literature also reveals that a firm may not always have the resources it requires to develop a source of sustainable competitive advantage and it must therefore devise sustainable methods of acquiring these resources from other firms. The legal, political and socio-economic environmental factors also influence the firm and the strategic choices it is likely to make. Cultural and socio-economic practices inform firms in bundling of their resources which in effect leads to formation of unique core competencies.

In addition to contributing to literature on the linkage between firm resources, core competencies and sustainable competitive advantage, this paper also suggests areas for further research. The paper identifies a gap on literature in development of sustainable competitive advantage in an industry where firms share common, homogenous and mobile resources. Secondly the study also identifies a gap in literature on the role of core competencies in bundling resources to attain resources with desirable characteristics of heterogeneity, inimitability and immobility. Future research needs to to examine the complementarities between the RBV and the RDT in acquiring resources which are not controlled by the firm and that are key to development of sustainable competitive advantage for the firm in need of them. Secondly further studies need to be carried out to examine how the institutional theory complements the resource based view theory in formation of key core competencies through organizational cultures and practices.

\section{References}

Barnejee, S. (2001). Corporate Environmental Strategies and Actions. Management Decision, 39(1), 36-44. http://dx.doi.org/10.1108/EUM0000000005405

Barney J. (1991). Firm Resources and Sustained Competitive Advantage. Journal of Management, 17(1), 99-120 http://dx.doi.org/10.11771014920639101700108

Barney J. (2001). Is the Resource Based View a Useful Perspective for Strategic Management Research? Yes. The Academy Management Review, 26(1), 41-56. http://dx.doi.org/10.5465/AMR.2001.4011939

Danneels, E. (2002). The dynamics of product innovation and firm competences. Strategic Management Journal, 23(12), 1095-1121. http://dx.doi.org/10.1002/smj.275

Danneels, E. (2008). Organizational Antecedents of Second Order Competences. Strategic Management Journal, 29(5), 519-543. http://dx.doi.org/10.1002/smj.684

DiMaggio, P., \& Powell, W. (1983). The iron cage revisited: institutional isomorphism and collective rationality in organizational fields. American Sociological Review, 4(2), 147-160. http://dx.doi.org/10.17323/1726-3247-2010-1-34-56

Duysters, G., \& Hagedoorn, J. (1996). The Effect of Core Competence Building on Company Performance. The Journal of High Technology Management Research, 11(1), 75-91. http://dx.doi.org/10.1.508.4350 
Enz, C. A. (2008, February). Creating a Competitive Advantage by Building Resource Capability: The case of Outback Steak House, Korea. Cornell Hospitaility Quartelry, 49, 73-78. http://dx.doi.org/10.1177/1938965507311648

Garvin D. (1993). Manufacturing Strategic Planning. California Management Review, 35(4), 85-106 http://dx.doi.org/10.2307/41166756

Ghemawat, P. (1986). Sustainable Advantage. Havard Business Review, 64, 53-58.

Grant, R. (1991). The Resource-Based Theory of Competitive Advantage: Implications for Strategy Formulation. California Management Review, 33(3), 114-135.

Hodgson, G. (1998). Evolutionary and Competence Based Theories of the Firm. Journal of Economic Studies, 25, 125-26. http://dx.doi.org/10.1.1.320.2749

Hoffer, C., \& Schendel, D. (1978). Strategy formulation: Analytical concepts. St. Paul, MN: West.

Huang, K., Dyerson, R., Wu, L., \& Harindranath, G. (2015). From Temporary Competitive Advantage to Sustainable Competitive Advantage. British Journal of Management, 26(4), 617-636. http://dx.doi.org/10.1111/1467-8551.12104

Kilika, J. M. (2012). Institutional Context, University Industry Collaboration, Human Resource Development Infrastructure and Performance of Universities in Kenya. Unpublished Doctoral Thesis. Nairobi: University of Nairobi.

Lippman, S., \& Rumelt, R. (1982). Uncertain Irritability: An Analysis of Inter Firm Differences in Efficiency under Competition. Bell Journal of Economics, 13, 418-438. http://dx.doi.org/10.2307/3003464

Ljungquist, U. (2013). Going Practical on the Core Competence Concept: On Links, Levels, Time and Context, Knoweldge and Process Management. Knowledge and Process Management, 20(4), 223-231. http://dx.doi.org/10.1002/kpm.1425

Meyer, J., \& Rowan, B. (1991). Institutionalized Organizations: Formal Structure as Myth and Ceremony. American Journal of Sociology, 8, 3340-363. http://dx.doi.org/10.1086/226550

Meyer, K. E., Estrin, S., Bhaumik, S. K., \& Peng, M. W. (2009b). Institutions, Resources and Entry Strategies in Emerging Economies. Strategic Management Journal, 30, 61-80.

Mintzberg, H. (1979). The Structuring of Organizations. Prentice-Hall: Englewood Cliffs, NJ.

Newbert, S. (2008) Value, Rareness, Competitive Advantage and Performance: A Conceptual Level Empirical Investigation of the Resource Based View of the Firm. Strategic Management Journal, 29(7), 745-768. http://dx.doi.org/10.1002/smj:686

Pedler, M., Burgoyne, J., \& Boydell, T. (1991). The Learning Company: A Strategy for Sustainable Development. London: McGraw-Hill

Penrose, E. (1959). The Theory of the Growth of the Firm. Oxford Unviersity Press, Oxford.

Peteraf, M. (1993). The Cornerstones of Competitive Advantage: A Resource Based View. Strategic Management Journal, 14(3), 179-191. http://dx.doi.org/10.1002/smj:4250140303

Peteraf, M. A., \& Barney, J. B. (2003). Unraveling the resource- based tangle. Journal of Management, 36(1), 349-372. http://dx.doi.org/10.1177/0149206309350775

Pfeffer, J., \& Salancik, G. R. (1978). The External Control of Organizations: A Resource Dependence Perspective. Harper \& Row: New York.

Porter, M. (1980). Competitive Strategy: Techniques for Analyzing Industries and Competitors. The free Press: New York.

Porter, M. E. (1981). The contributions of industrial organization to strategic management. Academy of Management Review, 6, 609-620. http://dx.doi.org/10.1002/smj.369

Porter, M. E. (1985). Competitive Advantage: Creating and Sustaining Superior Performance. Free Press: New York.

Porter, M. E. (1996). What is Strategy? Havard Business Review, 1, 95-117 http://dx.doi.org/10.1002/smj.4250121008 
Porter, M. E. (1998). Competitive Advantage. The free Press.

Prahalad, C. K., \& Hamel, G. (1990). The Core Competence of the Corporation. Journal of Strategy and Leadership, 32(3), 449. http://dx.doi.org/10.L108/10878570410699249

Sillince J. A. A. (2006). Resources and Organizational Identities: The Role of Rhetoric in the Creation of Competitive Advantage. Management Communication Quarterly, 20(2), 186-213. http://dx.doi.org/10.1177/08933/8906293587

Sirmon, D. G., Hitt, M. A., Ireland, R. D., \& Gilbert, B. A. (2011). Resource Orchestration to create Competitive Advantage: Breadth, Depth and Life Cycle Effects. Journal of Management, 37(5), 1390-1412. http://dx.doi.org/10.1177/1049206310385695

Teece, D., \& Pisano, G. (1994). The Dynamic Capabilities of Firms: An Introduction. Industrial and Corporate Change, 3, 547-556. http://dx.doi.org/10.1093/icc/3.3.537

Zack, M. H. (1999). Developing a Knowledge Strategy. California Management Review, 125(2), $215-223$. http://dx.doi.org/10.1016/j-ijpe.2010.03.012

Zott, C., \& Amit, R. (2007). Business Model Design and the Performance of Entrepreneurial Firms. Organization Science, 18(2), 181-199. http://dx.doi.org/10.1287/orsc.1060.0232 